\title{
BMJ Open The labour market, psychosocial outcomes and health conditions in cancer survivors: protocol for a nationwide longitudinal survey 2 and 5 years after cancer diagnosis (the VICAN survey)
}

\begin{abstract}
Anne-Deborah Bouhnik, ${ }^{1,2}$ Marc-Karim Bendiane, ${ }^{1,2,3}$ Sebastien Cortaredona, ${ }^{1,2,3}$ Luis Sagaon Teyssier, ${ }^{1,2,3}$ Dominique Rey, ${ }^{1,2,3}$ Cyril Berenger, ${ }^{1,2,3}$ Valerie Seror, ${ }^{1,2}$ Patrick Peretti-Watel, ${ }^{1,2,3}$ members of the VICAN Group
\end{abstract}

To cite: Bouhnik A-D, Bendiane M-K, Cortaredona S, et al. The labour market, psychosocial outcomes and health conditions in cancer survivors: protocol for a nationwide longitudinal survey 2 and 5 years after cancer diagnosis (the VICAN survey). BMJ Open 2015;5: e005971. doi:10.1136/ bmjopen-2014-005971

- Prepublication history for this paper is available online. To view these files please visit the journal online (http://dx.doi.org/10.1136/ bmjopen-2014-005971).

Received 27 June 2014 Revised 17 November 2014 Accepted 23 December 2014

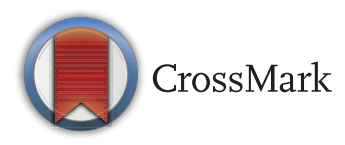

For numbered affiliations see end of article.

\section{Correspondence to} Anne-Deborah Bouhnik; anne-deborah.bouhnik@ inserm.fr

\section{ABSTRACT}

Introduction: Today, a growing need exists for greater research into cancer survivorship, focusing on different spheres of the day-to-day life of diagnosed patients. This article describes the design and implementation of VICAN (Vle après le CANcer), a national survey on French cancer survivors.

Method and analysis: The target population included patients aged 18-82, diagnosed with cancer between January and June 2010, and registered in one of the three main French Health Insurance Schemes. It was restricted to 12 tumour sites. Sampling was stratified using a non-proportional allocation, based on age at diagnosis (18-52 and 53-82) and tumour site. Data were collected from telephone interviews with patients 2 and 5 years after diagnosis, a medical survey completed by the physician who initiated cancer treatment, and information from the national medicoadministrative database on reimbursement data and hospital discharge records. First data collection, 2 years after diagnosis, occurred between March and December 2012. Second data collection, 5 years after diagnosis, will be conducted in 2015. Analyses will be conducted on various outcomes: quality of life, health status and psychosocial conditions, with a particular focus on the impact of cancer diagnosis on the labour market. The variety of measurements included in the survey will enable us to control a wide range of factors. Ethics and dissemination: The methodology of the VICAN survey was approved by three national ethics commissions. Results of the study will be disseminated through national and international research conferences, and in articles published in international peer-reviewed journals.

\section{BACKGROUND}

Over the past decades, the incidence of most cancers has increased in developed

\section{Strengths and limitations of this study}

- This longitudinal survey investigates various topics related to cancer survivorship among a large population-based national sample of 4349 adults in France.

- The survey combines three sources of data: patient-reported outcomes, medical records and medicoadministrative databases.

- The use of medicoadministrative databases to select participants from among all those initially contacted, resulted in a high number of ineligible patients and a high number of patients whose eligibility remained unknown.

countries. ${ }^{1-3}$ At the same time, earlier diagnoses and more effective treatments have led to increased survival rates for most cancers. ${ }^{4-6}$ As a result, the population of cancer survivors is steadily increasing. This has led to a growing number of studies on cancer survivorship and the consideration of survivorship as a major stage in the continuum of care. $^{7-10}$

These studies have shown that many survivors face psychological, physical and social challenges that may impact their daily lives and their quality of life. Cancer therapies can create long-term health problems that may become permanent, such as fatigue, ${ }^{11} 12$ pain, ${ }^{13}{ }^{12}$ lymphoedema, ${ }^{14}$ infertility, ${ }^{15-17}$ cognitive impairment, ${ }^{18}$ urinary disorders ${ }^{19}$ and sexual dysfunction. ${ }^{20}{ }^{21}$ Cancer survivors are also at increased risk of developing a second cancer or treatment-related heart failure $^{22} 23$ years after the diagnosis of the initial cancer. Regarding the psychological effects, episodes of depression, anxiety and 
distress may occur even a long time after cancer diagnosis. Furthermore, depressive symptoms are often described in cancer survivors, with prevalence as high as $40 \%$ reported in those with lung cancer. However, these patients are often underdiagnosed and undertreated. ${ }^{24-26}$ The epidemiological evolution resulting from medical progress in screening and treatments has prompted the need to reconsider the position of people with cancer in terms of the disease consequences, in particular at the occupational level. Indeed, the short-term and long-term consequences of cancer treatment, as well as the initial diagnosis itself, can strongly influence not only workbased opportunities in terms of access into employment and a return-to-work but also workplace activities focusing on ensuring job tenure. In addition to the physical ${ }^{27}$ and cognitive $^{28}$ limitations that may impair the participation of cancer survivors in the labour market, the role of negative relationships with co-workers ${ }^{29}{ }^{30}$ and employers ${ }^{31}$ is an important consideration. Remaining in employment and the prospect of a return to work have both been identified as key aspects for cancer survivors' quality of life. ${ }^{32-34}$ Several studies have underlined the need for comprehensive long-term care for cancer survivors ${ }^{35} 36$ and emphasised the lack of data on the evolution of side effects of cancer treatments over time. Despite pain being one of the symptoms that most affect patients' lives, the management of persistent pain is still often suboptimal. ${ }^{37}$ To ensure a better quality of life for patients, to organise appropriate long-term follow-up for them, and to allow them to regain their place in society, it is necessary to acquire a greater understanding of the midterm and long-term physical and psychological consequences of the disease and their social impact. It was in this context that the American Cancer Society's Studies of Cancer Survivors (SCS I-II) were initiated in 2007 in the USA. ${ }^{38}$ In Europe, similar studies have been implemented, for example, the PROFILES registry in the Netherlands in 2011. ${ }^{39}$ Following the recommendations of the French national 2009-2013 Cancer Plan to financially support surveys collecting data on cancer survivors' living conditions, ${ }^{40}$ the French National Cancer Institute (INCa) entrusted the implementation of VICAN (VIe après le CANcer) - a national survey on French cancer survivorsto the INSERM UMR 912 research unit.

\section{Objectives of the VICAN survey}

The aim of the VICAN survey is to document the living conditions of adult patients with cancer 2 and 5 years after cancer diagnosis. More specifically, the objectives are:

- First, to study the labour market outcomes. As an increasing number of people of working age are being diagnosed with cancer, growing importance is being attached to the workplace consequences of cancer. ${ }^{41-43}$ However, some important aspects of this issue are often neglected and need further research. ${ }^{44}$ In particular, the effect of cancer on an individual's employability needs to be disentangled from the effects of their socioeconomic status. Integrating variables related to work characteristics will help us to understand the true effect of living with cancer on the individual survivor's economic situation. Important individual characteristics, such as economic status and psychosocial issues, may either weaken or strengthen the effects that cancer has on job tenure and employability, and need to be documented. Furthermore, the role of medical outcomes is often missing in related research studies. By simultaneously integrating variables related to an individual's economic situation, their socioeconomic characteristics and medical data related to cancer, this survey will be able to shed some important light on the deleterious effects of cancer on working life at the individual level. The collection of data over a 5 -year period after diagnosis will also allow us to describe the impact of cancer on professional trajectories and the transitions between different states in the workplace. ${ }^{43}$

- Second, to determine the nature, prevalence and temporality of factors that may negatively affect or improve the quality of life and daily life of cancer survivors, and to study their evolution at 2 and 5 years after cancer diagnosis. Health-related quality of life is a key element both in the evaluation of life after cancer diagnosis and in creating a balanced life for the individual. Accordingly, understanding the factors affecting long-term quality of life remains an important research issue. ${ }^{38} 45$ Particular attention will be given in the survey to health status (treatment follow-up, management of treatment-related side effects, comorbidities, cancer relapse or second cancer) and also to psychosocial conditions (lifestyle behaviours, perceived discrimination, family and social support). Relevant questions, for example, include: Are cancer sequelae diagnosed and treated well? What is the impact of long-term sequelae on people with cancer where the prognosis is very good? Do the changes in lifestyle behaviours impact on quality of life? What is the role of social inequalities?

- Third, to evaluate the physical, psychological and social needs of cancer survivors. For example, one of the questions to ask is whether patients are satisfied with the information provided on treatment side effects or on the risk of treatment-induced infertility?

- Fourth, to compare new data with results from a French survey performed in 2004..$^{31414345-49}$

\section{A study 2 and 5 years after cancer diagnosis}

In this article, we consider that cancer survivorship begins after primary treatment. ${ }^{50}$ Therefore, we chose to implement the first part of the survey in patients 2 years after cancer diagnosis, effectively in the 'recovery' phase, which follows the primary treatment phase. This choice allowed us to interview survivors who had cancer with intermediate or poor prognosis. 
The second interview will occur in 2015, 5 years after cancer diagnosis, effectively at the end of the 'early monitoring phase' (2-5 years after diagnosis), which is the period where the risk of relapse and of treatment side effects is greatest.

From the point of view of labour market outcomes, the choice of a survey 2 years after cancer diagnosis was based on the specificity of the social security system in France. State legislation provides considerable protection to workers and the impact of cancer diagnosis or of other chronic diseases on employability is quite different compared with many other countries, especially those where patients are confronted with a job-lock situation, whereby they are effectively tied to the same company in order to benefit from healthcare (eg, in the USA). Indeed, in France and other countries with similar social security systems, little is known about the role played by sociodemographic, socioeconomic and clinical characteristics on the capacity of patients to retain their professional situation after diagnosis. Literature about other countries has demonstrated that the deleterious effect of cancer on professional trajectories begins to manifest itself at an early stage after diagnosis, and persists beyond the first 2 years. ${ }^{51}$ This justifies the choice of interviewing the same individuals 2 and 5 years after diagnosis, as the information gathered may help us to understand the situation with which French cancer survivors are confronted within the labour market, and to analyse the extent to which the effects of cancer on labour market outcomes are irreversible.

This article aims to describe the design and implementation of this innovative and ambitious survey, which combines patients' self-reported data, information collected from their medical records and administrative records for healthcare use.

\section{METHODS}

\section{Definition of target population}

The survey targeted adult patients with cancer diagnosed between January and June 2010. As the active treatment phase does not usually last more than 12 months, targeted patients had experienced life after cancer for at least 1 year when first interviewed 2 years after diagnosis. People under 18 years at diagnosis were excluded from the survey for legal reasons. Those over 82 years at diagnosis were also excluded for practical reasons. Although the latter group represent $7 \%$ of cancer incidence in France, ${ }^{52}$ they would have been aged $>84$ at the time of first data collection, and telephone interviews with this age group can be quite difficult for several reasons: they frequently live in institutions with no personal telephone line; they are prone to refuse telephone surveys; hearing problems frequently complicate the interview. ${ }^{53} 54$

Health insurance is compulsory in France. All those treated for cancer are registered in the Long Duration Disease File of the National Health Insurance Fund
(ALD file), with a code detailing the tumour site. For practical reasons, we restricted the survey to patients registered with one of the three main Health Insurance Schemes (Caisse Nationale de l'Assurance Maladie des Travailleurs Salariés (CNAMTS) for salaried workers, Régime Social des Indépendants (RSI) for self-employed workers, Mutuelle Sociale Agricole (MSA) for farmers), which together cover more than 90\% of the French population. Eligibility was restricted to French-speaking patients diagnosed with first malignant cancer and living in France for at least 2 years.

\section{Sample stratified according to age and tumour site}

As our main objective was to investigate the barriers to and drivers of patients' return to work, we overrepresented those aged $<54$ at diagnosis, as they were aged $<56$ at the time of the survey and therefore too young for retirement or early retirement schemes. Accordingly, we defined two age strata-18-52 and 53-82 at diagnosis-with a weight of $50 \%$ for each stratum.

We also restricted the survey to 12 tumour sites that accounted for $88 \%$ of global cancer incidence in France in 2012. ${ }^{55}$ Site selection depended on four criteria: global incidence, incidence by age (in line with our two age strata above), 2-year survival rate and level of scientific interest (eg, we planned to focus on lung cancer because of recent improvements in associated survival). Selected tumour sites included cancers with good prognosis (breast, prostate and thyroid cancers, melanoma), others with intermediate prognosis (colorectal, bladder, kidney, cervical, endometrial and upper aerodigestive tract cancers, non-Hodgkin lymphoma) and one with poor prognosis (lung cancer). ${ }^{56}$

\section{Sampling design}

A simple random sampling design was applied to each of the 24 strata ( 2 age ranges $\times 12$ tumour sites) using the ALD file. In order to over-represent people aged $<54$ at diagnosis and relatively rare tumour sites, we did not opt for proportional allocation. Sample sizes were determined a priori within each stratum for a global sample size of $\mathrm{N}=6000$ (see table 1). The objective was to have enough statistical power to conduct analyses separately for certain tumour sites, and to complete data collection within a reasonable period of time. Based on the experience of the survey carried out in 2004, which allowed us to use data collected for many topics, ${ }^{46}$ including employment, ${ }^{31} 41 \quad 43$ the chosen targeted sizes per tumour site and per age range seemed a good compromise. We excluded prostate, bladder and endometrial cancers from the age stratum '18-52 at diagnosis', because these cancers have a much higher incidence among older people. Conversely, we excluded thyroid cancer from the stratum '53-82 at diagnosis', because its incidence sharply decreases after age $55 .{ }^{52}$

For each stratum, we estimated the number of contacts necessary to achieve the target size using the response rate observed for the 2004 survey. We also took into 
Table 1 Sampling design: age at diagnosis and tumour sites strata (VICAN)

\begin{tabular}{|c|c|c|c|c|c|c|}
\hline \multirow[b]{2}{*}{$\begin{array}{l}\text { Age at diagnosis } \\
\text { Cancer type }\end{array}$} & \multicolumn{3}{|c|}{ 18-52 Years old } & \multicolumn{3}{|c|}{ 53-82 Years old } \\
\hline & $\begin{array}{l}\text { Percentage } \\
\text { in ALD file }\end{array}$ & $\begin{array}{l}\text { Expected } \\
\text { percentage } \\
\text { in sample }\end{array}$ & $\begin{array}{l}\text { Expected } \\
\text { size }\end{array}$ & $\begin{array}{l}\text { Percentage } \\
\text { in ALD file }\end{array}$ & $\begin{array}{l}\text { Expected } \\
\text { percentage } \\
\text { in sample }\end{array}$ & $\begin{array}{l}\text { Expected } \\
\text { size }\end{array}$ \\
\hline Breast cancer & 40.6 & 26.7 & 800 & 17.1 & 16.7 & 500 \\
\hline Prostate cancer & - & - & - & 39.2 & 20.0 & 600 \\
\hline Melanoma & 7.3 & 10.0 & 300 & 2.1 & 5.0 & 150 \\
\hline Thyroid cancer & 9.7 & 10.0 & 300 & - & - & - \\
\hline Colorectal cancer & 8.7 & 11.7 & 350 & 14.2 & 10.0 & 300 \\
\hline $\begin{array}{l}\text { Upper aerodigestive tract } \\
\text { cancers }\end{array}$ & 9.8 & 10.0 & 300 & 4.6 & 6.7 & 200 \\
\hline Bladder cancer & - & - & - & 3.7 & 6.7 & 200 \\
\hline Kidney cancer & 3.2 & 5.0 & 150 & 3.1 & 5.0 & 150 \\
\hline Non-Hodgkin lymphoma & 5.3 & 6.7 & 200 & 3.5 & 6.7 & 200 \\
\hline Cervical cancer & 4.3 & 6.7 & 200 & 2.5 & 6.7 & 200 \\
\hline Endometrial cancer & - & - & - & 0.5 & 3.3 & 100 \\
\hline Lung cancer & 11.1 & 13.3 & 400 & 9.5 & 13.3 & 400 \\
\hline Total & 100 & 100 & 3000 & 100 & 100 & 3000 \\
\hline
\end{tabular}

Reading example: among patients aged 18-52 at diagnosis, for the nine selected tumour sites, $40.6 \%$ of patients registered in the ALD file in 2012 had breast cancer. The expected figure was much lower in the sample: $26.7 \%(\mathrm{~N}=800)$.

VICAN, Vle après le CANcer.

account the difference in recruitment procedures between both surveys. For example, the desired sample size for the stratum 'breast cancer/18-52 at diagnosis' was $\mathrm{N}=800$ in the VICAN study. In 2004, the observed response rate for this population was 59.7\%. However, in that survey, patients were recruited by telephone by physicians from the National Health Insurance Fund, and the global response rate was $53.7 \%$. Instead, in 2012, for the first data collection of VICAN, we planned to recruit participants by postal mail (see below). Accordingly, we expected a lower response rate. A survey conducted in 2007 (among patients with diabetes ${ }^{57}$ ) with the same recruitment procedure (a postal letter sent by the National Health Insurance Fund) had a response rate of $45 \%$. We expected a similar global response rate for the first data collection of VICAN. Therefore, in 2012, for patients with breast cancer diagnosed at age $18-52$, the expected response rate was $59.7 \% \times 45 \% / 53.7 \%=50.1 \%$. Consequently, 1597 patients had to be contacted to recruit 800 participants.

As we planned to recruit 6000 participants, with an expected response rate of 45\%, $13333(6000 / 0.45)$ people registered in the ALD file should have been contacted. However, in the 2004 survey, a number of those contacted proved to be ineligible for various reasons, including inaccurate diagnosis encoded in the ALD file, and hospitalisations and deceases at the time of the survey. Taking what had happened in the 2004 survey into account, we decided to slightly increase the number of scheduled contacts. In the end, 16429 patients were contacted.

\section{Data collection procedure}

Each selected patient received a letter inviting them to participate in the survey, sent by the National Health Insurance Fund. It did not mention the INCa or the word 'cancer', only the tumour site. For example, women with a diagnosis of breast cancer were asked to participate in a survey about their 'breast disease'. This approach was chosen because in the 2004 survey $7 \%$ of participants never used the word 'cancer' during their interview. ${ }^{46}$ The letter also mentioned that information would be collected from participants' medical and administrative records. Those who agreed to participate had to send back a signed informed consent letter. Those who did not respond were considered nonrespondents. One dunning letter was sent.

In 2012, participants were interviewed using the computer-assisted telephone interview (CATI) system. A postal questionnaire was proposed to people with lung or upper aerodigestive tract cancer, as their condition could have hampered their ability to respond orally.

\section{Data collected 2 years after diagnosis}

The CATI interview questionnaire dealt with many topics: sociodemographic background and socioeconomic status, circumstances of diagnosis, relationships with the healthcare system and health professionals, treatments received and perceived side effects. The word cancer was never mentioned. The questionnaire also included items related to perceived discrimination, social support, couple relationships, sexuality since diagnosis and fertility preservation. Lifestyle-related outcomes such as diet and physical activity, and alcohol and tobacco use were documented as well, and several validated scales evaluated quality of life, fatigue and pain. Health-related quality of life was assessed using the French version of the SF12 scale. ${ }^{58}$ Cancer-related fatigue was evaluated using the EORTC QLQ scale. ${ }^{59}$ Pain was estimated using two validated 
scales: the DN4 and ID-Pain questionnaires. ${ }^{60} \quad 61$ Moreover, since our survey focused on the impact of cancer on employment, a large part of the questionnaire was dedicated to this topic. Participants were asked about their working life during the study period (occupational status at the time of diagnosis and changes of status over the study period) and their working conditions (type of job, work contract, work schedules and income). They were also asked about the number and duration of periods of sick leave they had taken because of cancer. In addition, they were asked about perceived difficulty at work, and any work adjustments they had made or that had been proposed to them because of the disease.

For each participant, a medical survey was conducted with the physician who initiated cancer treatment, to collect detailed information regarding tumour histology (stage, grade, size) and treatments received. We also collected information from the national SNIIR-AM database, which includes financial reimbursement data (for physicians' and other health professionals' consultations, and for prescribed drugs) as well as hospital discharge records. ${ }^{62}$ We also collected data measured at the residential area level to investigate spatial inequalities: socioeconomic hardship indexes ${ }^{63} 64$ and measures of healthcare availability/accessibility (general practices, hospitals).

The patient and medical questionnaires are all available on the INCa website. ${ }^{65}$

\section{First data collection}

The first period of data collection, 2 years after diagnosis, occurred between March and December 2012.
Telephone interviews lasted on average $40 \mathrm{~min}$. Among those with lung or upper aerodigestive tract cancer who had the choice between a telephonic or postal interview, $68 \%$ asked for the latter.

Among the 16429 patients initially contacted, 6529 returned the signed informed consent form (figure 1). Patient eligibility was evaluated using three sources: a very brief questionnaire completed by patients and returned with their consent, SNIIR-AM data and the medical survey. In this context, among the 6529 individuals who provided signed informed consent, 1653 were excluded because of non-eligibility. Similarly, among the 9900 individuals who did not return the consent form, 1750 were identified as non-eligible. Consequently, of the 8279 individuals whose eligibility or non-eligibility could be ascertained, only $58.9 \%$ were effectively eligible (55.1\% and $63.6 \%$ among those aged 53-82 and aged 18-52 at diagnosis, respectively). The proportion of eligible people was markedly lower than expected, especially among those aged 53-82 at diagnosis.

The main reasons for ineligibility included inaccurate diagnosis (for $51.5 \%$ of ineligible patients: benign or second cancers, or errors in ALD file regarding the tumour site), inappropriate delay between diagnosis and survey (for $21.7 \%$ of ineligible patients: in most cases late recording in the ALD file), and patient death before the survey (for $16.4 \%$ of ineligible patients). In line with the recommendations of the American Association for Public Opinion Research, in order to compute a response rate, we assumed that the proportion of eligible people was identical among those who did not return the informed consent letter ('unknown eligibility'). ${ }^{66}$ The resulting response rates were close to

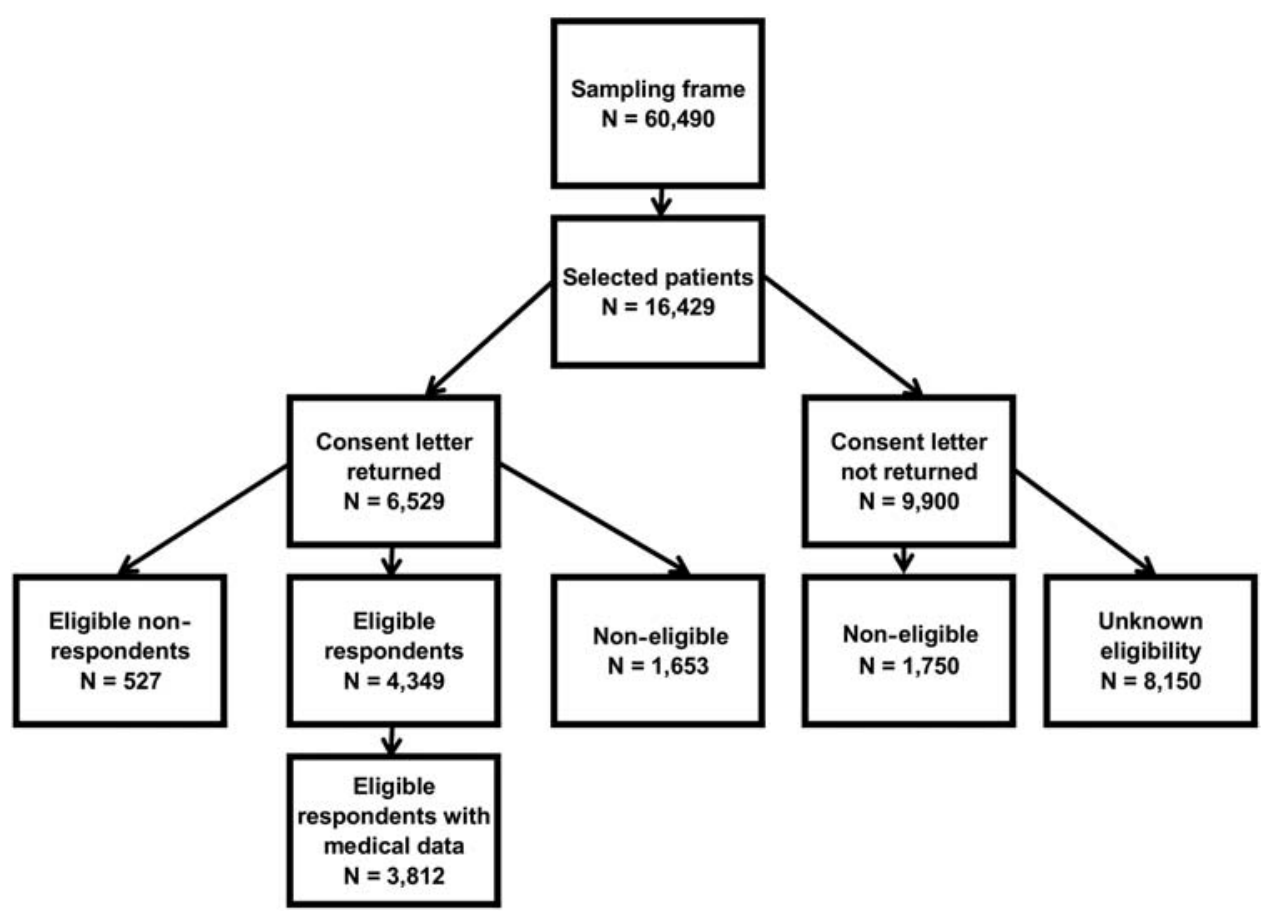

Figure 1 Sample selection pathway (VICAN, Vle après le CANcer). 
our expectations $(42.8 \%$ for the age stratum ' $18-52$ at diagnosis' and $44.5 \%$ for the age stratum '53-82 at diagnosis', providing an average of $43.7 \%$ ). Owing to the high proportion of ineligible people, the final sample size was only $\mathrm{N}=4349$.

Table 2 details the sample according to age and tumour site. Across the agextumour site strata, the response rate varied between $37 \%$ (for women aged 53-82 at diagnosis of endometrial cancer) and 52\% (18-52×non-Hodgkin lymphoma).

With respect to the medical survey, data collection took place between March 2012 and March 2013. After several reminders by phone and letters, it was completed for $87.7 \%$ of participants. SNIIR-AM data were collected for all participants.

\section{Weighting procedures}

As we used a stratified random sampling design with non-proportional allocation (see table 1), we first computed sampling weights as reciprocals of the probabilities of selection in each stratum. Second, as we collected data from the SNIIR-AM file for all contacted patients, we had the opportunity to compare eligible respondents with eligible non-respondents.

Available information included gender, age, tumour site and socioeconomic hardship index. ${ }^{63}$ We also expected that patients' health status was correlated to participation. Accordingly, we built an indicator of cancer progression using SNIIR-AM data for every patient contacted. We considered that patients who met one of the following criteria had progressive cancer: second cancer diagnosed since 2011, treatment with chemotherapy, radiotherapy or targeted therapy in 2012, admission to a palliative care unit in 2012 and death.

The proportion of women was higher among respondents $(52.8 \%$ vs $41.1 \%$ among non-respondents). Respondents were also younger on average than non-

\begin{tabular}{lrrr}
$\begin{array}{l}\text { Table } 2 \text { Final sample: age at diagnosis and tumour sites } \\
\text { strata (VICAN) }\end{array}$ \\
\hline \multicolumn{4}{c}{$\begin{array}{l}\text { Age at } \\
\text { diagnosis }\end{array}$} \\
\cline { 2 - 4 } Cancer type & $\mathbf{1 8 - 5 2}$ & $\mathbf{5 3 - 8 2}$ & Total \\
\hline Breast cancer & 971 & 379 & 1350 \\
Prostate cancer & - & 479 & 479 \\
Melanoma & 162 & 114 & 276 \\
Thyroid cancer & 181 & - & 181 \\
Colorectal cancer & 258 & 229 & 487 \\
Upper aerodigestive tract cancers & 153 & 131 & 284 \\
Bladder cancer & - & 143 & 143 \\
Kidney cancer & 108 & 110 & 218 \\
Non-Hodgkin lymphoma & 163 & 122 & 285 \\
Cervical cancer & 97 & 78 & 175 \\
Endometrial cancer & - & 75 & 75 \\
Lung cancer & 136 & 260 & 396 \\
Total & 2241 & 2108 & 4349 \\
\hline VICAN, Vle après le CANcer. & & &
\end{tabular}

respondents (60.4 vs 64.7 years), while non-respondents lived more frequently in areas with a high level of socioeconomic hardship (table 3). Breast cancer was markedly over-represented among respondents (35.1\% among respondents vs $22.4 \%$ among non-respondents), while upper aerodigestive tract and lung cancers were under-represented (overall $8.9 \%$ vs $17.2 \%$ ). The proportion of individuals with progressive cancer was significantly higher among non-respondents $(21.8 \%$ vs $17.4 \%)$.

As gender, age, socioeconomic hardship, tumour site and cancer progression all had a significant impact on participation, we adjusted initial weights for these five variables. The final weights were created using an iterative process (ranking ratio estimation). Thanks to the resulting weights, the marginal distribution for each of these variables was the same among all respondents $(\mathrm{N}=4349)$, among eligible patients $(\mathrm{N}=4876)$ and among patients whose eligibility status remained unknown $(\mathrm{N}=8150)$.

\section{Second data collection}

The National Health Insurance Fund will keep a matching file in order to propose participation to the same

Table 3 Comparison between eligible respondents and eligible non-respondents (VICAN)

\begin{tabular}{|c|c|c|}
\hline & $\begin{array}{l}\text { Respondents } \\
(\mathrm{N}=4349)\end{array}$ & $\begin{array}{l}\text { Non-respondents } \\
(\mathrm{N}=527)\end{array}$ \\
\hline & \multicolumn{2}{|l|}{ Per cent column } \\
\hline \multicolumn{3}{|l|}{ Gender } \\
\hline Men & 47.2 & 58.9 \\
\hline Women & 52.8 & $41.1^{\star \star *}$ \\
\hline Age: mean (SE) & $60.4(11.4)$ & $64.7(11.5)^{\star \star \star}$ \\
\hline \multicolumn{3}{|c|}{ Social deprivation index } \\
\hline$<1$ st quartile & 20.3 & 14.4 \\
\hline (1st-3rd quartiles) & 33.4 & 29.1 \\
\hline >3rd quartile & 46.3 & $56.5^{\star \star \star}$ \\
\hline \multicolumn{3}{|l|}{ Cancer type } \\
\hline Breast cancer & 35.1 & 22.4 \\
\hline Prostate cancer & 24.8 & 29.6 \\
\hline Melanoma & 3.1 & 3.1 \\
\hline Thyroid cancer & 2.0 & 1.4 \\
\hline Colorectal cancer & 11.8 & 13.3 \\
\hline $\begin{array}{l}\text { Upper } \\
\text { aerodigestive tract } \\
\text { cancers }\end{array}$ & 4.0 & 9.1 \\
\hline Bladder cancer & 4.5 & 4.8 \\
\hline Kidney cancer & 3.4 & 3.6 \\
\hline $\begin{array}{l}\text { Non-Hodgkin } \\
\text { lymphoma }\end{array}$ & 3.2 & 2.9 \\
\hline Cervical cancer & 1.3 & 0.9 \\
\hline Endometrial cancer & 1.8 & 0.8 \\
\hline Lung cancer & 4.9 & $8.1^{\star \star *}$ \\
\hline \multicolumn{3}{|c|}{ Cancer progression since diagnosis } \\
\hline No & 82.6 & 78.2 \\
\hline Yes & 17.4 & $21.8^{* \star *}$ \\
\hline
\end{tabular}


participants 5 years after their cancer diagnosis. This second collection of data will occur in 2015 .

\section{Planned statistical analysis}

Data analyses will be conducted using SPSS software (PASW Statistics 18, V.18.0.3), Stata/SE software (V.12.1) or R (V.3.0.2). Cross-sectional and longitudinal analyses will be performed. For the former, multivariate linear or logistic regressions will be used, depending on the nature of the outcomes. For longitudinal analyses, linear or logistic mixed-model regressions will be used, depending on the nature of the outcomes, to account for repeated measurements. The variety of measurements included in the survey will enable us to control for a wide range of factors. A continuous-time Markov process model will be implemented to evaluate the impact of cancer diagnosis on mobility between the different states of the labour market (eg, employment, unemployment, retirement, inactivity).

\section{DISCUSSION}

\section{Objectives of the survey}

Before discussing the survey's objectives, we must highlight that we collected two kinds of data: retrospective data (eg, concerning circumstances of diagnosis and treatments received) and data related to participants' current living conditions. Analyses using retrospective data may be influenced by selection bias, as only 'survivors at 2 years' were interviewed and not everyone initially diagnosed with cancer. However, this bias was certainly limited for tumour sites associated with a very good survival rate 2 years after diagnosis.

The VICAN survey has two main objectives. First, it was designed in close cooperation with the INCa, which is the official French state agency in charge of coordinating public policy related to the fight against cancer. From this perspective, the VICAN survey will be useful for public healthcare policy evaluation and orientation, in the short to medium term. For example, in order to improve the way patients are informed of cancer diagnosis, the Cancer Plan 2009-2013 approved the generalisation of the 'Diagnostic Disclosure Procedure', ${ }^{40} 67$ whose context and content are precisely defined. Accordingly, specific questions were introduced in the first questionnaire of the VICAN survey to assess the real world implementation of this measure. Second, VICAN was designed to encourage social sciences research on 'cancer survivorship' in the French context, as psychosocial issues dominate medical issues in this specific phase of the cancer trajectory. ${ }^{1068}$

\section{Using medicoadministrative databases}

Thanks to the specificities of the French healthcare system, we had the opportunity to use medicoadministrative databases (ALD and SNIIR-AM files). These databases are now widely used for research purposes in many fields ${ }^{69-72}$ and provide an effective way to contact cancer survivors. In other countries, similar samples have been created as subsamples of very large general population surveys ${ }^{73}$ or from cancer registries covering the whole territory, ${ }^{38}$ but such surveys/registries are not available in France. Moreover, these medicoadministrative databases allowed us to target specific populations (especially regarding tumour site and time since diagnosis) and to collect data on respondents as well as nonrespondents (in order to detect and correct for participation biases). These databases also provide detailed and reliable data regarding healthcare utilisation, unlike asking patients to self-report healthcare utilisation, which is both time-consuming and liable to recall bias. It is true, however, that many studies have shown that the effects of such biases on reported outcomes are minor. ${ }^{74-77}$

Despite their value, the use of medicoadministrative databases raises legal and technical issues that complicate the design of the survey. These databases also contain various kinds of inaccuracies, especially since they were not initially designed as research tools. In the VICAN survey, these limitations are illustrated by the relatively high level of ineligible patients among those who were initially contacted.

\section{Author affiliations}

${ }^{1}$ INSERM, UMR912 "Economics and Social Sciences Applied to Health \& Analysis of Medical Information" (SESSTIM), Marseille, France

${ }^{2}$ Aix Marseille University, UMR_S912, IRD, Marseille, France

${ }^{3}$ ORS PACA, Southeastern Health Regional Observatory, Marseille, France

Collaborators Members of the VICAN Group: Thomas Aparicio, Emmanuel Babin, François Beck, Robert Benamouzig, M-KB, CB, Dominique Bessette, A-DB, Philippe-Jean Bousquet, Marie-Claude Cabanel-Gicquel, Marianick Cavallini-Lambert, Michèle Chantry, Claire Chauvet, SC, Véronique Danguy, Michel Dorval, Jean-Baptiste Herbet, Laetitia Huiart, Xavier Joutard, Anne-Gaëlle Le Corroller-Soriano, Julien Mancini, Mégane Meresse, Jean-François Morere, Herman Nabi, Alain Paraponaris, PP-W, Marie Preau, Christel Protiere, Frédérique Retornaze, DR, Benoit Riandey, Luis Sagaon-Teyssier, Aurélia Tison, VS, Archana Singh-Manoux, Catherine Thieblemont, Pierre Verger

Contributors A-DB, M-KB, LST, DR, VS and PP-W contributed to the conception, design and management of the study. A-DB, CB, M-KB and PP-W contributed to the data collection. A-DB, M-KB, LST, SC, CB and PP-W contributed to the data analysis. A-DB, SC, LST, DR and PP-W contributed to the drafting of the manuscript. All authors critically revised successive drafts of the manuscript and approved the final version.

Funding This study was funded by The National Institute of Cancer (INCa), "Contrat de recherche et développement no 05-2011".

\section{Competing interests None.}

Ethics approval The study methodology was approved by three national ethics commissions: the CCTIRS (Comité Consultatif sur le Traitement de l'Information en Matière de Recherche dans le Domaine de la Santé, study registered under no 11-143), the ISP (Institute of Public Health, study registered under no C11-63) and the CNIL (French Commission on Individual Data Protection and Public Liberties, study registered under no 911290). Confidentiality is assured for all participants with regard to any personal responses and information provided, as all data collected are anonymised. Results of the study will be disseminated through national and international research conferences, and in articles published in international peer-reviewed journals.

Provenance and peer review Not commissioned; externally peer reviewed.

Data sharing statement The INCa will promote and organise open access to the dataset for all scientists interested in this survey before the end of 2014. 
Open Access This is an Open Access article distributed in accordance with the Creative Commons Attribution Non Commercial (CC BY-NC 4.0) license, which permits others to distribute, remix, adapt, build upon this work noncommercially, and license their derivative works on different terms, provided the original work is properly cited and the use is non-commercial. See: http:// creativecommons.org/licenses/by-nc/4.0/

\section{REFERENCES}

1. Kanavos P. The rising burden of cancer in the developing world. Ann Oncol 2006;17(Suppl 8):viii15-23.

2. Arnold M, Karim-Kos HE, Coebergh JW, et al. Recent trends in incidence of five common cancers in 26 European countries since 1988: analysis of the European Cancer Observatory. Eur J Cancer 2013; in press.

3. Ferlay J, Steliarova-Foucher E, Lortet-Tieulent J, et al. Cancer incidence and mortality patterns in Europe: estimates for 40 countries in 2012. Eur J Cancer 2013;49:1374-403.

4. Bosetti C, Bertuccio P, Malvezzi M, et al. Cancer mortality in Europe, 2005-2009, and an overview of trends since 1980. Ann Oncol 2013;24:2657-71.

5. Verdecchia A, Guzzinati S, Francisci S, et al. Survival trends in European cancer patients diagnosed from 1988 to 1999. Eur J Cancer 2009;45:1042-66.

6. Verdecchia A, Francisci S, Brenner $\mathrm{H}$, et al. Recent cancer survival in Europe: a 2000-02 period analysis of EUROCARE-4 data. Lancet Oncol 2007:8:784-96.

7. McCabe MS. Looking beyond survival survivorship care is critical to the future of oncology. Oncology (Williston Park) 2007:21:398.

8. Rowland JH, Hewitt M, Ganz PA. Cancer survivorship: a new challenge in delivering quality cancer care. J Clin Oncol 2006;24:5101-4.

9. Ayanian JZ, Jacobsen PB. Enhancing research on cancer survivors. $J$ Clin Oncol 2006;24:5149-53.

10. Grunfeld E. Looking beyond survival: how are we looking at survivorship? J Clin Oncol 2006;24:5166-9.

11. Pertl MM, Quigley J, Hevey D. 'I'm not complaining because l'm alive': barriers to the emergence of a discourse of cancer-related fatigue. Psychol Health 2014;29:141-61.

12. Pachman DR, Barton DL, Swetz KM, et al. Troublesome symptoms in cancer survivors: fatigue, insomnia, neuropathy, and pain. J Clin Oncol 2012;30:3687-96.

13. Marchettini P. More on pain semantics. Eur J Pain 2008;12:251 author reply 252.

14. Petrek JA, Senie RT, Peters M, et al. Lymphedema in a cohort of breast carcinoma survivors 20 years after diagnosis. Cancer 2001;92:1368-77.

15. Agarwal A, Allamaneni SS. Disruption of spermatogenesis by the cancer disease process. J Natl Cancer Inst Monogr 2005(34):9-12.

16. Armuand GM, Wettergren L, Rodriguez-Wallberg KA, et al. Desire for children, difficulties achieving a pregnancy, and infertility distress 3 to 7 years after cancer diagnosis. Support Care Cancer 2014;22:2805-12.

17. Trivers KF, Fink AK, Partridge $\mathrm{AH}$, et al. Estimates of young breast cancer survivors at risk for infertility in the U.S. Oncologist 2014:19:814-22.

18. Rey $\mathrm{D}$, Bouhnik AD, Mancini J, et al. Self-reported cognitive impairment after breast cancer treatment in young women from the ELIPPSE40 cohort: the long-term impact of chemotherapy. Breast $J$ 2012;18:406-14.

19. Penson DF, McLerran D, Feng Z, et al. 5-Year urinary and sexual outcomes after radical prostatectomy: results from the prostate cancer outcomes study. J Urol 2005;173:1701-5.

20. Rasmusson EM, Plantin L, Elmerstig E. 'Did they think I would understand all that on my own?' A questionnaire study about sexuality with Swedish cancer patients. Eur J Cancer Care (Engl) 2013;22:361-9.

21. Bober SL, Varela VS. Sexuality in adult cancer survivors: challenges and intervention. J Clin Oncol 2012;30:3712-19.

22. Bowles EJ, Wellman R, Feigelson HS, et al. Risk of heart failure in breast cancer patients after anthracycline and trastuzumab treatment: a retrospective cohort study. J Natl Cancer Inst 2012;104:1293-305.

23. Suter TM, Cook-Bruns N, Barton C. Cardiotoxicity associated with trastuzumab (Herceptin) therapy in the treatment of metastatic breast cancer. Breast 2004;13:173-83.

24. Alfano CM, Rowland $\mathrm{JH}$. Recovery issues in cancer survivorship: a new challenge for supportive care. Cancer J 2006;12:432-43.
25. Sharpe M, Walker J, Holm Hansen C, et al. Integrated collabourative care for comorbid major depression in patients with cancer (SMaRT Oncology-2): a multicentre randomised controlled effectiveness trial. Lancet 2014;384:1099-108.

26. Suppli NP, Johansen C, Christensen J, et al. Increased risk for depression after breast cancer: a nationwide population-based cohort study of associated factors in Denmark, 1998-2011. J Clin Oncol 2014;32:3831-9.

27. Chirikos TN, Russell-Jacobs A, Jacobsen PB. Functional impairment and the economic consequences of female breast cancer. Women Health 2002;36:1-20.

28. Schagen SB, van Dam FS, Muller MJ, et al. Cognitive deficits after postoperative adjuvant chemotherapy for breast carcinoma. Cancer 1999;85:640-50.

29. Greaves-Otte JG, Greaves J, Kruyt PM, et al. Problems at social re-integration of long-term cancer survivors. Eur $\mathrm{J}$ Cancer 1991;27:178-81.

30. Maunsell E, Brisson C, Dubois L, et al. Work problems after breast cancer: an exploratory qualitative study. Psychooncology 1999;8:467-73.

31. Paraponaris A, Teyssier LS, Ventelou B. Job tenure and self-reported workplace discrimination for cancer survivors 2 years after diagnosis: does employment legislation matter? Health Policy 2010;98:144-55.

32. Kobayashi K, Morita S, Shimonagayoshi M, et al. Effects of socioeconomic factors and cancer survivors' worries on their quality of life (QOL) in Japan. Psychooncology 2008;17:606-11.

33. Short PF, Vargo MM. Responding to employment concerns of cancer survivors. J Clin Oncol 2006:24:5138-41.

34. Taskila T, Lindbohm ML, Martikainen R, et al. Cancer survivors' received and needed social support from their work place and the occupational health services. Support Care Cancer 2006;14: 427-35.

35. Ganz PA, Hahn EE. Implementing a survivorship care plan for patients with breast cancer. J Clin Oncol 2008;26:759-67.

36. Grunfeld E. Optimizing follow-up after breast cancer treatment. Curr Opin Obstet Gynecol 2009;21:92-6.

37. Breivik H, Cherny N, Collett B, et al. Cancer-related pain: a pan-European survey of prevalence, treatment, and patient attitudes. Ann Oncol 2009;20:1420-33.

38. Smith T, Stein KD, Mehta CC, et al. The rationale, design, and implementation of the American Cancer Society's studies of cancer survivors. Cancer 2007;109:1-12.

39. van de Poll-Franse LV, Horevoorts N, van Eenbergen M, et al. The Patient Reported Outcomes Following Initial treatment and Long term Evaluation of Survivorship registry: scope, rationale and design of an infrastructure for the study of physical and psychosocial outcomes in cancer survivorship cohorts. Eur $J$ Cancer 2011;47:2188-94

40. http://www.e-cancer.fr/en/cancer-plan-2009-2013, 2013

41. Marino P, Luis Sagaon T, Laetitia M, et al. Sex differences in the return-to-work process of cancer survivors 2 years after diagnosis: results from a large French population-based sample. J Clin Oncol 2013;31:1277-84

42. Mak AK, Chaidaroon S, Fan G, et al. Unintended consequences: the social context of cancer survivors and work. J Cancer Surviv 2014;8:269-81.

43. Joutard X, Paraponaris A, Sagaon-Teyssier L, et al. Continuous-time Markov model for transitions between employment and nonemployment: the impact of a cancer diagnosis. Ann Econ Stat 2012:107/108:239-66.

44. de Boer AG, Taskila T, Ojajarvi A, et al. Cancer survivors and unemployment: a meta-analysis and meta-regression. JAMA 2009;301:753-62.

45. Le Corroller-Soriano AG, Bouhnik AD, Preau M, et al. Does cancer survivors' health-related quality of life depend on cancer type? Findings from a large French national sample 2 years after cancer diagnosis. Eur J Cancer Care (Engl) 2011;20:132-40.

46. Le Corroller-Soriano A, Malavolti L, Mermillod C. La vie deux ans après le diagnostic du cancer: une enquête en 2004 sur les conditions de vie des malades. Paris: La documentation française, 2008.

47. Mancini J, Rey D, Preau M, et al. Barriers to procreational intentions among cancer survivors 2 years after diagnosis: a French national cross-sectional survey. Psychooncology 2011;20:12-18.

48. Preau M, Bouhnik AD, Rey D, et al. Two years after cancer diagnosis, which couples become closer? Eur J Cancer Care (Engl) 2011;20:380-8.

49. Protiere $\mathrm{C}$, Moumjid N, Bouhnik AD, et al. Heterogeneity of cancer patient information-seeking behaviors. Med Decis Making 2012;32:362-75. 
50. Hewitt M, Greenfield S, Stovall E. From cancer patient to cancer survivor: lost in transition. Washington, DC: The National Academies Press, 2005.

51. Moran JR, Short PF, Hollenbeak CS. Long-term employment effects of surviving cancer. J Health Econ 2011;30:505-14.

52. Belot A, Grosclaude P, Bossard N, et al. Cancer incidence and mortality in France over the period 1980-2005. Rev Epidemiol Sante Publique 2008;56:159-75.

53. Groves RM, Biemer PP, Lyberg LE, et al. Telephone survey methodology. John Wiley \& Sons, 2001.

54. Beck F, Gautier A. Baromètre cancer 2010. Saint-Denis: INPES, 2012

55. https://lesdonnees.e-cancer.fr/les-fiches-de-synthese/29-incidencemortalite/38-ensemble-des-cancers/22-epidemiologie-des-cancersen-france-metropolitaine-incidence-et-mortalite.html\#ind2, 2013.

56. Mazeau-Woynar V, Cerf N. Survie attendue des patients atteints de cancers en France: état des lieux. Paris: Institut national du cancer, 2010.

57. Jourdan-Da Silva N. Instauration d'une insulinothérapie dans le diabète de type 2: données épidémiologiques, étude entred 20012003 [thesis] 2005

58. Burdine JN, Felix MR, Abel AL, et al. The SF-12 as a population health measure: an exploratory examination of potential for application. Health Serv Res 2000;35:885-904.

59. Groenvold M, Klee MC, Sprangers MA, et al. Validation of the EORTC QLQ-C30 quality of life questionnaire through combined qualitative and quantitative assessment of patient-observer agreement. J Clin Epidemiol 1997;50:441-50.

60. Portenoy R. Development and testing of a neuropathic pain screening questionnaire: ID pain. Curr Med Res Opin 2006;22:1555-65.

61. Bouhassira D, Attal N, Alchaar $\mathrm{H}$, et al. Comparison of pain syndromes associated with nervous or somatic lesions and development of a new neuropathic pain diagnostic questionnaire (DN4). Pain 2005;114:29-36.

62. Lenormand $\mathrm{F}$. Le système d'information de l'assurance maladie, le SNIIRAM et les échantillons de bénéficiaires. Courr Stat 2005;113-114 33-51.

63. Carstairs V, Morris R. Deprivation and health in Scotland. Aberdeen: Aberdeen University Press, 1991.

64. Rey G, Rican S, Jougla E. Mesure des inégalités de mortalité par cause de décès. Approche écologique à l'aide d'un indice de désavantage social. Bull Epidémiol Hebdomadaire 2011;8-9.
65. http://www.e-cancer.fr/component/docman/doc_download/12164-lavie-deux-ans-apres-un-diagnostic-de-cancer-de-lannonce-a-laprescancer-2014-annexes, 2014.

66. The American Association for Public Opinion Research. Standard definitions: final dispositions of case codes and outcome rates for surveys. 7th edn. 2011.

67. Dolbeault S, Bredart A. Cancer diagnosis disclosure: the French experience. New Challenges in Communication with Cancer Patients. New-York: Springer, 2013.

68. Stanton AL. Psychosocial concerns and interventions for cancer survivors. J Clin Oncol 2006;24:5132-7.

69. Blotiere PO, Weill A, Ricordeau P, et al. Perforations and haemorrhages after colonoscopy in 2010: a study based on comprehensive French health insurance data (SNIIRAM). Clin Res Hepatol Gastroenterol 2014;38:112-17.

70. Fagot JP, Boutrelle A, Ricordeau P, et al. HPV vaccination in France: uptake, costs and issues for the National Health Insurance. Vaccine 2011;29:3610-16.

71. Neumann A, Maura G, Weill A, et al. Comparative effectiveness of rosuvastatin versus simvastatin in primary prevention among new users: a cohort study in the French national health insurance database. Pharmacoepidemiol Drug Saf 2014;23:240-50.

72. Santin G, Geoffroy B, Benezet L, et al. In an occupational health surveillance study, auxiliary data from administrative health and occupational databases effectively corrected for nonresponse. J Clin Epidemiol 2014:67:722-30.

73. Elliott J, Fallows A, Staetsky L, et al. The health and well-being of cancer survivors in the UK: findings from a population-based survey. Br J Cancer 2011;105(Suppl 1):S11-20.

74. Friedenreich CM, Howe GR, Miller AB. An investigation of recall bias in the reporting of past food intake among breast cancer cases and controls. Ann Epidemiol 1991;1:439-53.

75. Friedenreich CM, Howe GR, Miller AB. The effect of recall bias on the association of calorie-providing nutrients and breast cancer. Epidemiology 1991;2:424-9.

76. Giovannucci E, Stampfer MJ, Colditz GA, et al. Recall and selection bias in reporting past alcohol consumption among breast cancer cases. Cancer Causes Control 1993;4:441-8.

77. Vrijheid M, Deltour I, Krewski D, et al. The effects of recall errors and of selection bias in epidemiologic studies of mobile phone use and cancer risk. J Expo Sci Environ Epidemiol 2006;16: 371-84 